\section{References}

1 Geddis D C. Children in cars: results of an observational study in New Zealand. NZ Med J 1979; 90: 468-71.

2 Neumann C G, Neumann A K, Cockrell M E, Banani S. Factors associated with child use of automobile restraining devices. Am J Dis Child 1974; 128: 469-74.

3 Miller J R, Pless I B. Child automobile restraints: evaluation of health education. Pediatrics 1977; 59: 907-11.

4 Williams A F. Observed child restraint use in automobiles. Am J Dis Child 1976; 130: 1311-7.

5 Pless I B, Roghmann K J. Safety restraints for children in automobiles: who uses them? Can J Public Health 1978; 69: 289-92.
6 Department of Health. Growth of pre-school children in New Zealand. Management Services and Research Unit Special Report Series No 44. New Zealand: Department of Health, 1975.

7 Reisinger K S, Williams A F. Evaluation of programs designed to increase the protection of infants in cars. Pediatrics 1978; 62: 280-7.

8 Pless I B. Accident prevention and health educationback to the drawing board. Pediatrics 1978 ; 62: 431-5.

Correspondence to Dr D C Geddis, PO Box 6042, Dunedin, New Zealand.

Received 17 February 1982

\title{
Prolonged foreign body impaction in the oesophagus
}

\author{
L SPITZ AND J HIRSIG
}

Department of Paediatric Surgery, The Hospital for Sick Children, London

SUMMARY The severe consequences of prolonged impaction in the oesophagus of a fairly radiolucent foreign object (aluminium can top) in 2 children are reported. The value of endoscopy in cases of unexplained dysphagia, even in the presence of normal radiographic examination, is stressed.

Ingestion of foreign bodies by infants and small children is common. In many cases, the foreign object passes uneventfully through the gastrointestinal tract. ${ }^{12}$ Impaction occurs most often in the upper third of the oesophagus. Generally, the history, clinical symptoms, and plain $x$-ray investigation establish the correct diagnosis. Occasionally, as a result of mild initial symptoms or the ingestion of a radiolucent object, the diagnosis of an oesophageal foreign body is delayed for several months or even years with severe consequences or even mortality.

The aluminium ring can top is a classical example of a fairly radiolucent foreign body which may easily be overlooked on a plain radiograph. Delay in the extraction of an impacted can top in the oesophagus may result in transmural ulceration into the mediastinum with consequent abscess formation, ${ }^{3}$ haemorrhage from one of the great blood vessels, ${ }^{4}$ or stricture formation.

\section{Patients}

Case 1. This 8-year-old girl had been investigated at age 2 years because of a 6-month history of recurrent upper respiratory tract infections and for feeding problems since birth. Plain $x$-ray film of the chest showed a slight widening of the superior mediastinum. A contrast swallow showed a small hiatus hernia with minimal gastro-oesophageal reflux. The child was reviewed at regular intervals for the next 6 months, and as her weight remained on the 50th centile for her age, she was eventually referred back to the family practitioner for further management.

She continued to experience difficulty with swallowing and failed to thrive. At age 8, she was admitted to her local hospital with a further respiratory tract infection. Her weight had fallen to below the 3rd centile for her age. A barium swallow (Fig. 1, left) showed a large multilocular diverticulum at the level of the thoracic inlet with a long distal oesophageal stricture extending to the level of the 3rd vertebra. Tomography of the superior mediastinum clearly demonstrated the presence of a pull-ring situated at the thoracic inlet (Fig. 1, right). Oesophagoscopy confirmed the presence of the pull-ring within the upper oesophagus and the distally strictured lumen. The ring was firmly embedded in the oesophagus and in view of the possible adherence to adjacent blood vessels no attempt was made to extract it. A feeding gastrostomy was fashioned as the child was unable to swallow even thin liquid food at this stage. Three weeks after admission the affected oesophagus was explored via a combined cervical and mediastinal approach through an upper median sternotomy incision. The upper third of the oesophagus was found to have been virtually 


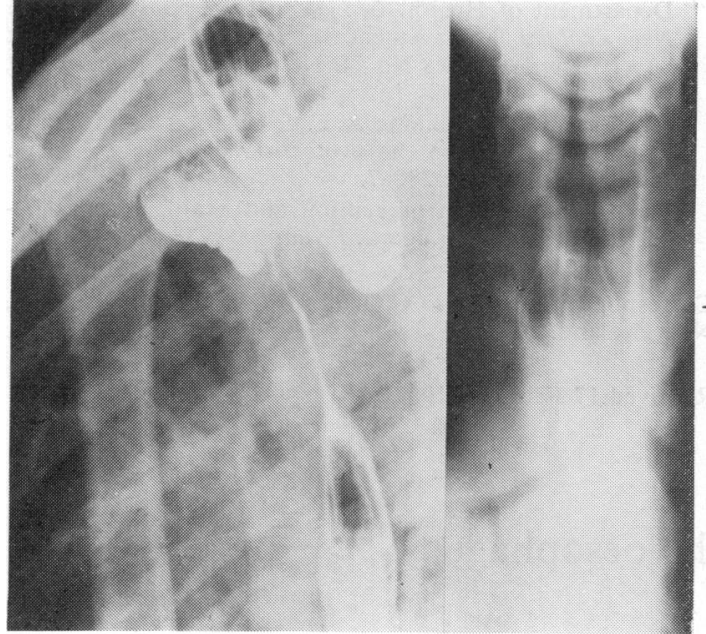

Fig. 1 (Left). Barium swallow showing 2 false diverticula in the upper oesophagus with a long narrow stricture extending into the mid-oesophagus. (Right). Tomogram of the neck and superior mediastinum showing the can-ring at the thoracic inlet.

replaced by granulation tissue and after extracting the foreign body, reconstitution of the oesophagus was impossible due to extensive ulceration. The distal oesophagus was oversewn and the proximal end brought out on to the surface as a cervical oesophagostomy.

Three months later, oesophageal replacement by gastric interposition was carried out via a left thoraco-abdominal approach. The fundus of the stomach was anastomosed to the upper cervical oesophagus. The postoperative course was uneventful except for temporary incoordination of deglutition and late abscess formation in the right cervical region at the site of the oesophagostomy. The child is now well, eating normally, and thriving.

Case 2. An 18-month-old boy was admitted to an outlying hospital in acute respiratory distress having choked on a piece of sausage. An emergency tracheostomy was performed and the child was transferred for further investigation of a longstanding history of dysphagia and failure to thrive (weight below 3rd centile). A plain radiograph of the chest was unremarkable. A barium swallow showed a persistent narrowing at the junction between the upper and middle thirds of the oesophagus (Fig. 2). This part of the oesophagus appeared to be displaced anteriorly and to the left by an extrinsic mass. The provisional diagnosis was a foregut duplication cyst. An oesophagoscopy showed the

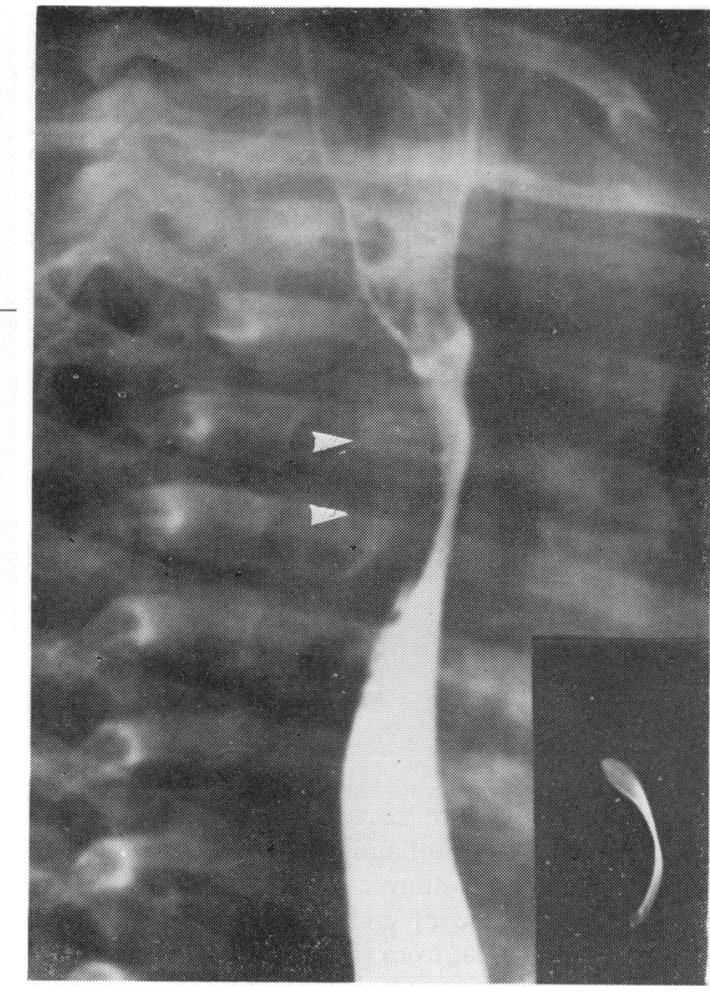

Fig. 2 Barium swallow showing a deformity and narrowing in the upper oesophagus. Within the concavity of the stenosed area the outline of a can tab could be identified (arrowed). The inset shows radiograpically the can tab after surgical remova!.

stricture at $12 \mathrm{~cm}$ from the incisor teeth but no mucosal abnormality was noted.

Bronchoscopy was normal. At exploration via a right posterolateral thoracotomy, a $3 \times 4 \mathrm{~cm}$ cystic mass was found lateral and posterior to the upper oesophagus. The mass was densely adherent to the surrounding structures and to the oesophagus. During a difficult mobilisation the cyst ruptured revealing its contents of purulent fluid in which a metal can top was present. After excision of the abscess wall, a small $0.5 \mathrm{~cm}$ defect in the right lateral wall of the oesophagus was repaired. The postoperative course was uneventful.

\section{Discussion}

These two cases stress the problems in the detection of fairly radiolucent ingested foreign bodies and the consequences of prolonged impaction of such an object within the alimentary canal. In the case of 
the aluminium can top, a lateral chest radiograph in which the foreign object is projected away from the spine, could be of some diagnostic value. Upper gastrointestinal endoscopy, with or without a flexible fibrescope, should be considered in every case of unexplained swallowing difficulty, even if the contrast study fails to show an abnormality.

A plea is made to manufacturers of metal cans either to incorporate a distinctive radio-opaque marker on the pull-ring, or to ensure that it cannot easily be detached from the can.

We thank Dr M H Wansbrough-Jones for referring the first case to us for surgical treatment from St George's Hospital, London.

\section{References}

1 Spitz L. Management of ingested foreign bodies in childhood. $\mathrm{Br}$ Med J 1971 ; iv: 469-72.

2 Baraka A, Bikhazi G. Oesophageal foreign bodies. Br Med J 1975; i: 561-3.

3 Levick R K, Spitz L, Robinson A. The 'invisible' can top. Br J Radiol 1977; 50: 594-6.

4 Burrington J D. Aluminium 'pop tops'. A hazard to child health. JAMA 1976; 235 : 2614-7.

Correspondence to Professor L Spitz, The Hospital for Sick Children, Great Ormond Street, London WCIN 3JH.

Received 23 February 1982

\title{
Serum pancreatic lipase as a screening test for cystic fibrosis
}

\author{
KAREL ADRIAENSSENS AND LODE VAN RIEL
}

Provincial Institute for Hygiene, Antwerp, Belgium

SUMMARY Pancreatic lipase catalyses the hydrolysis of emulsified triglycerides to form a transparent solution of monoglycerides and fatty acids. Levels of serum pancreatic lipase were measured in neonates known to have cystic fibrosis and compared with levels in control infants. During the first weeks of life infants with cystic fibrosis had raised serum pancreatic lipase values in parallel with raised serum trypsin values. A simple and specific turbidimetric dried blood spot assay for serum pancreatic lipase was used as a screening test for cystic fibrosis in the neonate.

It has been reported that the presence of a raised immunoreactive trypsin value in a dried blood spot is a useful screening test for neonates with cystic fibrosis (CF). ${ }^{1-3}$

Since pancreatic lipase activity parallels that of pancreatic trypsin during intrauterine and postnatal development ${ }^{4}$ (as it does in a variety of pancreatic disorders 5 ), the serum pancreatic lipase values in neonates with CF may be important. We studied the blood pancreatic lipase values during the first few weeks of life of neonates known to have CF and compared them with controls, and from this a simple screening test on dried blood spots was developed.

\section{Patients and controls}

Between September 1979 and May 1981, 7 neonates with CF were identified out of 26705 prospectively screened using the two-tier immunoreactive trypsin test. ${ }^{13} \mathrm{CF}$ was confirmed in these 7 infants by at least two abnormal sweat tests. Each had clinical symptoms of CF and was receiving treatment. Twenty dried blood samples had been collected from these 7 infants when aged between 5 days and 9 months, and these were available for a retrospective pancreatic lipase assay. Dried blood samples, each from the same batch as the CF sample, were used as controls, but the lipase values from the older Guthrie cards were lower because they had been stored for longer.

\section{Method}

The turbidimetric serum pancreatic lipase (EC 3.1.1.3) assay, ${ }^{6}$ available as the lipase monotest (Boehringer-Mannheim), was adapted for dried blood spots. The lipase reagent was prepared as recommended by the manufacturer. Dried blood standards (lipase activity 0,60,120,240, and 480 $\mathrm{U} / \mathrm{l}$ serum) were prepared from appropriate dilutions of the kit serum standard with saline, and mixed with washed and packed red blood cells to a final haematocrit value of $50 \%$, or were added to dried blood spots containing no lipase (inactivated by heating ${ }^{7}$ ). To elute the lipase from the dried blood sample or standard, $1.5 \mathrm{ml}$ of cooled $\left(0^{\circ}-4^{\circ} \mathrm{C}\right)$ lipase reagent was added to a dried blood spot, $6 \mathrm{~mm}$ in diameter, and placed in a refrigerator overnight or for at least 3 hours. As the samples were small and there was 